\title{
A Strategic Approach to the Transportation Planning Process
}

\author{
Edward A. Mierzejewski \\ University of South Florida
}

\begin{abstract}
The underlying premise of the urban transportation planning process is that we can forecast the future. The process typically develops 20-year forecasts of traffic volumes on each link of the transportation network. Planners then attempt to devise a master plan that represents an optimal solution for the forecasted conditions. The reality is that we cannot predict the future. Imponderable and unpredictable events will shape the future in ways we cannot hope to anticipate. In addition, social and political bias is a strong contributor to errors in anticipating future events and to our willingness to deal with uncertainty. This paper identifies possible remedies for dealing with uncertainty and bias, including better analytical methods, better process methods, and methods to counter bias. An evaluation of various remedies is performed and practical measures that can be applied to the urban transportation planning process are identified. Finally, specific recommended modifications to the urban transportation planning process are outlined.
\end{abstract}

\section{A World of Change, Uncertainty, and Bias}

"It's tough to tell the future."

So begins a report distributed by the Florida Department of Transportation (1994) as background for the 2020 Florida Transportation Plan. It goes on to note: 
Analyzing historical and current trends to forecast conditions 20 or more years into the future has been compared to throwing darts at a moving board under a strobe light. The dynamic nature of social, economic, and political activities in the United States and Florida creates too many uncertainties for foolproof forecasting.

Twenty-five years earlier, Manheim (1979) noted, "We live in a world of rapid change." He identified three dimensions of change that are relevant to transportation systems: change in demand, change in technology, and change in values. We might also note a world of uncertainty-not only is change occurring, but it is occurring in ways that we cannot anticipate. Others have cited the uncertainty in future availability of resources (Neumann and Pecknold 1973) and in estimating costs (Wachs 1986; Pickrell 1990).

In addition to the objective fact of our inability to accurately predict the future, a major feature of urban transportation planning is the social and political bias that is evident in technical analyses. Recognition of uncertainty is routinely suppressed, bold assertions are made about future conditions, and forecasts are intentionally manipulated to promote politically-motivated conclusions. These features are particularly evident in the planning of large-scale transit guideway investments.

\section{The Urban Transportation Planning Technical Process}

Planning for urban transportation systems involves the application and analysis of technically complex simulation models within a highly political decisionmaking environment. The conventional process involves development of 20-year forecasts of socio-economic variables, such as population and employment, disaggregated into hundreds of traffic analysis zones of the typical metropolitan area. Based on the 20-year socio-economic forecasts, a series of sequential models are used to develop detailed forecasts of demands on the future transportation network. 


\section{Reality: Change Cannot Be Predicted with Certainty}

The underlying premise of the urban transportation planning process is that we can forecast the future. The reality is that the models are highly imprecise, the inputs to the models are impossible to predict, and the forecasted results are almost sure to miss the mark.

\section{Sources of Uncertainty in Transportation Planning Models}

Lowe and Richards (1983) identified three sources of error in transportation planning models: specification, calibration, and error in exogenous inputs. Limitations in the precision of the transportation planning models caused by specification and calibration error pale in comparison to the uncertainty of forecasting exogenous inputs. How precise can we be in forecasting social and economic factors 20 years into the future?

Look ahead 20 years into the future and imagine what the United States will be like. Specifically, try to estimate the nation's population and employment 20 years from now. Don't forget to account for factors such as future wars, major recessions, the reliability of crude oil supplies, U.S. immigration policy, and future fertility and death rates.

Now think about what Florida's share of your national estimate will be 20 years in the future. Don't forget to account for the future fall of Castro, the political situation in Haiti, future national retirement locational preferences, potential development moratoria, and supplies of potable water.

Now that you have addressed all these factors and are confident with your estimates of U.S. and Florida's population and employment, think about what an individual county with Florida, e.g. Hillsborough County's, share will be 20 years from now. Be sure to account for factors such as the status of rebuilding the Tampa Interstate, the commercial success of the Florida Aquarium, competition by Orlando for tourists, and major corporate relocations. Now, allocate the Hillsborough County share across 800 traffic analysis zones.

Seems like a pretty hopeless exercise, doesn't it? Yet, this is exactly what we do, every time we prepare a long range plan for an urbanized area. Moreover, 
advocates of major capital investments routinely claim to be able to estimate traffic volumes or transit ridership 20 years into the future on individual links of a hypothetical transportation network. We develop plans as if we could take a rifle shot 20 years into the future and predict the precise magnitude and distribution of activities within a region. The reality is quite different-more like a shotgun blast.

\section{Examples of Forecast Performance}

It can be instructive to review examples of the past performance of transportation forecasts to see just how accurate our forecasts have been. The examples presented in the following sections show that the track record of forecasts are not very reassuring.

Tampa Urban Area Transportation Study. In 1970, a comprehensive urban area transportation study was undertaken for Tampa, which developed traffic forecasts for the year 1985 (Barr and Dunlop 1970). A comparison of the actual 1985 traffic volumes was made with those forecasts made in 1970. Of 87 different links for which it was possible to compare actual 1985 traffic counts with those forecasted in 1970 , the errors ranged from -78 percent to +281 percent, with an average absolute link error of 57 percent. Moreover, these forecasts were for a 15-year period-insufficient by today's standards.

Tampa CBD Employment Forecasts. During the early- to mid-1980s, several forecasts were prepared of future employment in the Tampa central business district (CBD). As illustrated in Figure 1, forecasts were done for a downtown people mover (DPM) study, for a central business district development of regional impact (CBD DRI), and for several other conditions. Forecasts done in the early 1980 s projected CBD employment to be at 75,000 to 80,000 by the year 2000. In the mid-1980s, new forecasts were made. By then, it was clear that CBD employment was not on track to 80,000 by the year 2000 ; instead, it was forecast that employment would be in the 55,000 range by the year 2000 , but would still be approaching 90,000 by the year 2010 . The reality is that, in the years since 1980, employment in the Tampa CBD has been fairly flat, falling in the $28,000-30,000$ range in 1998 . The range of forecasts and the actual perfor- 


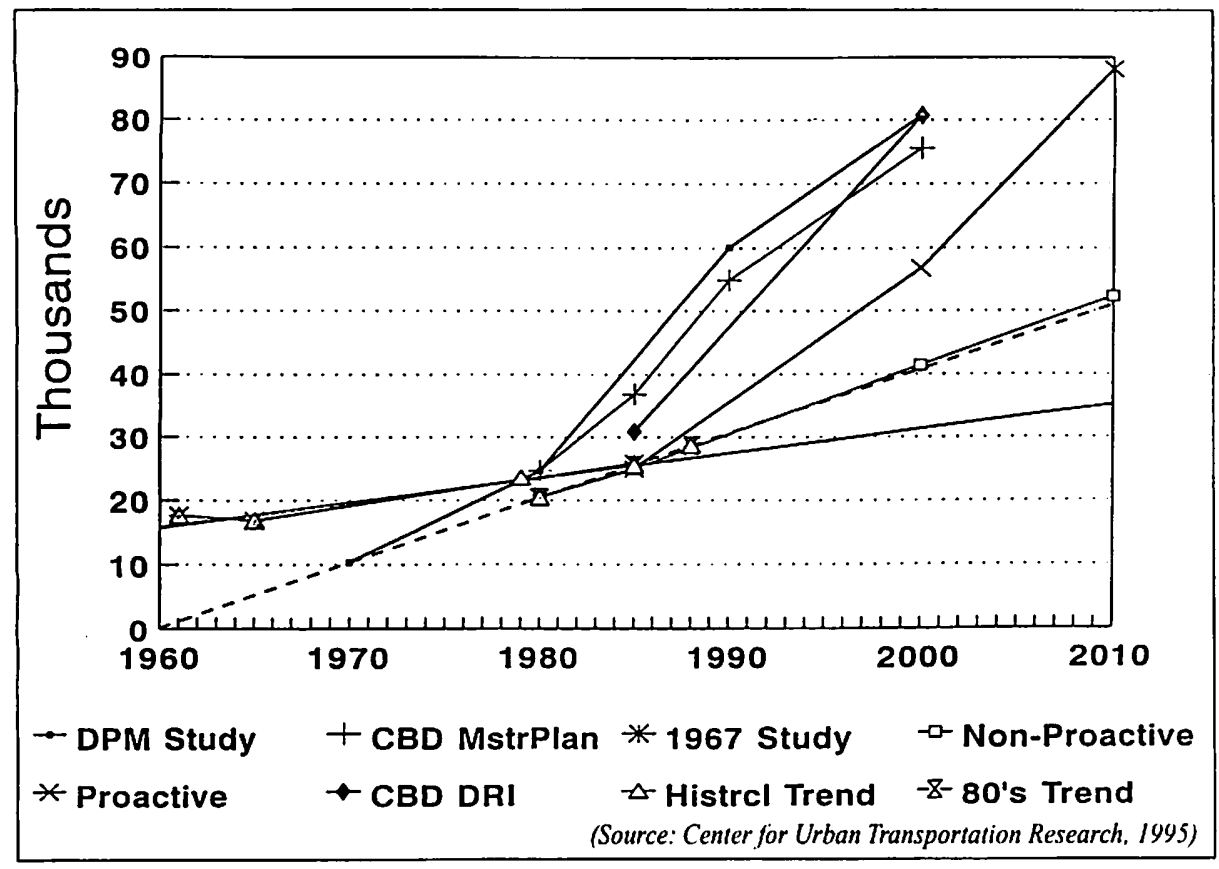

Figure 1. Tampa CBD employment forecasts.

mance demonstrate the extreme volatility of these model inputs, which, regrettably, have been used as the basis for major capital facility planning in the region, including a downtown people mover system, a rail transit system, and a massive freeway construction program.

Interstate Highway Estimates. An analysis of forecasts of traffic on urban interstates reported that traffic was overestimated by 21 percent and 24 percent, respectively, for three- and seven-year forecast periods (Pell and Meyberg 1983). The authors of the study concluded that ". . . one of the most damning practical criticisms [of the urban transportation planning process] is that the forecasts produced ... are incorrect."

British Case Studies. The Transport and Road Research Laboratory published a report (Mackinder and Evans 1981) in which forecasts from 44 British urban transportation studies undertaken between 1962 and 1971 were compared 
with actual occurrences. On average, population was overestimated by 20 percent and highway and public transit trips by 30 to 35 percent. If one were to measure the errors in forecasting the incremental change in various parameters, the results would be much worse: average forecasted population growth was three times the observed growth, while forecasts of the growth in total person trips were more than six times the observed growth.

Guideway Transit Case Studies. Pickrell (1990) examined the accuracy of forecasts for eight U.S. cities that invested in rail transit projects. Forecasts of ridership and costs that were the basis of local decisions to implement these systems were compared with the actual costs and ridership experienced. Ridership estimates were found to be consistently overestimated, while costs were consistently underestimated. The study noted that decisions to implement these major capital investments were made based on very small forecasted differences in performance between alternatives, whereas the actual performance of the selected alternatives were substantially different from the forecasts.

\section{Misinterpretation and Outright Bias} in Individual and Group Decisionmaking

The preceding section dealt with uncertainty and error primarily with respect to the inability of models to replicate observed conditions. This section deals with our inability to interpret data correctly, and even more importantly, the pervasiveness of outright bias in the decisionmaking process.

\section{Common Errors in Individual Perception}

Perhaps the poor performance of transportation planning models should not be surprising, since our individual intuitive judgments regarding cause and effect are often flawed. In their best-selling book, In Search of Excellence, Peters and Waterman (1984) cite the work of psychologists Tversky and Kahneman (1974), and conclude that "... people reason intuitively. They reason with simple decision rules, which is a simple way of saying that, in this complex world, they trust their gut." Unfortunately, gut feelings are not necessarily valid. 
Most people attempt to discriminate much more than their knowledge warrants (Behn and Vaupel 1982). Perhaps the most significant example of individual misperception is the comparative ease with which we can come up with after-the-fact explanations for events that we failed to predict (Fischoff 1977; Behn and Vaupel 1982; Hogarth 1987; Dawes 1988). When we reflect on a historical occurrence, we search for reasons why it was entirely predictable, even though before the event itself the evidence was very confusing.

\section{Socio-Political Bias in Forecasting and Decisionmaking}

Given the difficulty we have as individuals, can it be any wonder that group decisions are even more confounding? Such errors are even more difficult to deal with, because they demonstrate not only our lack of individual ability to deal objectively with information but also with the bias introduced by conflicting values. As observed by Ascher (1978), forecasts that underscore a priority that is out of political favor are likely to be ignored, whereas forecasts that support politically favorable positions are likely to be embraced.

Reliance on Myth and Metaphor. In his provocative analysis of the decision to build a rail transit system in Los Angeles, Jonathan Richmond (1995) describes the process whereby myths are constructed through images, symbols, and metaphors, which provide compelling messages on what is good and bad in our world. He believes that a central feature of myth development is the focus on a technology that can serve as the center of attention, one of simplicity and certainty. Technology serves as a symbol; rather than deal with the complex myriad problems that need to be solved, technology allows us to focus on the "easy fix" to all of our problems.

Making Forecasts Support Our Preconceptions. Too often our forecasts reflect what we desire, rather than what is likely to occur. As noted by the U.S. Department of Transportation and the Environmental Protection Agency, forecasted distributions of regional population and employment are often an erroneous input to the transportation planning models because of the influence of political compromise, rather than technical expertise (U.S. DOT 1993). Human 
nature being what it is, we are more willing to entertain evidence that supports our view of the world and are resistant to contradictory evidence (Hogarth 1987).

Ethics and Bias of Advocacy in Forecasting. Wachs (1986) relates tinkering with forecasts to the issue of professional ethics. He notes one study in which the models predicted "insufficient" rail ridership. To correct this situation, assumed highway speeds were reduced from $45 \mathrm{mph}$ to a "more realistic" $30 \mathrm{mph}$. This simple assumption substantially increased the forecast of rail ridership. He notes that most of the forecasts used in planning of U.S. rail transit systems are statements of advocacy, rather than unbiased estimates.

\section{Recommended Changes to the Urban Transportation Planning Process}

Our inability to control uncertainty dictates substantial changes in the way we do urban transportation planning. The assumption of a rational decisionmaking process that underlies current transportation practice does not exist. Rather, what has been observed is a technical process that is incapable of forecasting conditions 20 years into the future and a political process that systematically and deliberately contrives forecasts to justify preconceptions of decisionmakers.

In spite of uncertainty, we need to plan for the future and to move proactively toward the attainment of valued goals. Moreover, we can adopt planning practices that reduce bias in our decisionmaking process.

This section presents strategies considered to be most suitable for application to urban transportation planning, along with specific actions needed to incorporate them into the process.

\section{Define a Strategic Vision}

The transportation planning process should begin by articulating a strategic vision. This would best be accomplished as part of a comprehensive strategic planning process. We need to be able to articulate a vision of what we want our community to be "when it grows up."

The vision need not be a dramatic departure from the past. On the other hand, the vision might call for sweeping changes to the character of the area. The vision will need to incorporate land use, community development, protection of 
natural resources, and transportation. The vision will necessarily be strategic-it will incorporate the general desired features but will not rigidly define precise details, as these must be responsive to the unknowable future.

\section{Highlight Uncertainties through Strategic Planning}

Strengths, Weaknesses, Opportunities, and Threats. Once a strategic vision has been articulated, the recommended process would undertake a classical strategic planning approach that identifies strengths, weaknesses, opportunities, and threats to reaching the desired vision. This activity represents a radical departure from traditional planning practice, which evaluates all available information to estimate a single expected value for each variable. The product of the strategic planning process should be an identification of all conceivable risks and a proposed action for dealing with them.

Highlight Uncertainties. A critical element of a new process should be the articulation of all assumptions and all uncertainties associated with forecasting future conditions. This practice will require a new awareness on the part of professional staff of the importance of assumptions in the analytical process. However, it is vitally important that decisionmakers and the community be made fully aware of the uncertainties, particularly critical inputs to the transportation planning models: population, labor force, and employment.

Scenario Analysis/Ranges of Assumptions. The strategic planning process should explicitly consider specific ranges of assumptions, as captured in alternative scenarios of the future. In spite of best available projections, what is the chance that study area population, labor force or employment will be 10 percent higher or lower than the best guess estimate? Twenty percent higher? Errors of this magnitude need to be expected and anticipated.

\section{Promote Fexibility}

Once we admit the reality of uncertainty, flexibility becomes very important. In a future that holds unanticipated surprises, we need to place a high value on retaining future options.

Right-of-Way Protection. One measure that could be implemented to preserve future options and to emphasize flexibility is the early acquisition of trans- 
portation rights of way. While right-of-way preservation presents difficult political challenges, the benefits make it worthwhile.

Build-Later. The concept of a "build-later" alternative, as advocated by Chu and Polzin (1996), is recommended to be included in major investment studies. In contrast to current practice, in which end-states 20 or more years into the future are the basis for decisions today, the build-later alternative would result in the inclusion of major investment timing as an explicit analysis factor.

\section{Plan for Incremental Implementation}

Much of the research presented in this paper points toward the desirability of incremental implementation of major projects. One of the most controversial categories of transportation investments is the implementation of major fixed guideway transit projects, such as rail rapid transit systems. Risks and uncertainties, particularly as they relate to future ridership and costs, have often made it impossible to muster the necessary political support to implement such systems, which are typically represented in the form of optimistic assessments of outcomes 20 to 50 years into the future.

Can it be any surprise that elected officials are reluctant to commit to systems that will involve massive present costs in return for uncertain future benefits? Because we make only grandiose plans, all we have to show is plans, while we might actually implement something one step at a time. Such an approach might begin by offering express bus service using makeshift park-and-ride lots. As demand increases, permanent and perhaps more ideally-located park-andride facilities can be constructed.

As warranted by demand, dedicated high occupancy vehicle (HOV) facilities can be implemented or preferential bus treatments can be devised that allow buses to circumvent specific high congestion delay points. As each of these actions is taken, based on affirmation in the form of ridership, political support for the next increment of investment will build. Ultimately, the addition of a guideway transit system can be justified, with the park-and-ride infrastructure already in place. 
Place Greater Emphasis on the Short Run. Uncertainty increases with duration-not a major revelation, but, surprisingly, a fact that is frequently ignored. Regrettably, a condition of federal participation in projects has been assurance that improvements meet anticipated traffic levels 20 years following opening of the project. Moreover, this requirement will almost always negate the potential of systems and demand management actions as alternatives to major capital improvements.

The focus of transportation planning on the 20-year horizon needs to be changed; instead, more emphasis should be placed on current deficiencies, and on the five-year horizon. Rather than focus on the development of a static plan for 20 years into the future, a dynamic process is recommended that identifies improvement needs in five-year increments. Initially, as suggested by Pickrell (1990), alternative actions for coping with immediate deficiencies should be evaluated. Following this, forecasts would be made of conditions at five-year increments into the future. The emphasis should be on selecting a good short term plan, to meet the needs of the initial five-year period, with a sequence of improvements identified for each subsequent increment. In contrast to the current process, which is predicated on optimizing the response to a highly uncertain 20-year forecast, the recommended process is focused on optimizing responses in a shorter, five-year time frame, with an eye on the long term.

Alternatives that Can be Implemented in Usable Modules. An example was provided of an alternative approach to the implementation of guideway transit systems. Rather than focusing on a system justified with forecasts of demand decades into the future, the alternative approach called for incremental implementation beginning with temporary park-and-ride lots, transitioning to HOV, ultimately resulting in guideway transit, if warranted.

A modal alternative that merits much more consideration is that of exclusive busway systems. A major advantage of a busway system is that, if properly staged, even small increments provide notable operational advantages. Each increment offers improved levels of service for the bus system, contrasted with rail guideway alternatives, for which a substantial portion of the system must be 
completed in order to achieve any benefits. A recent paper by Martinelli (1994) provides ample evidence of the benefits afforded by busways. He notes that the busway combines the flexibility of a bus to go anywhere with the line haul characteristics of fixed guideway transit services, at substantially lower cost. The Ottawa and Pittsburgh exclusive busway systems are cited as examples of operational efficiency, the former carrying 210,000 passengers daily.

A key feature of the busway alternative is that it can be implemented in increments, each of which provides measurable benefits. An important implication of uncertainty is that technologies that can be implemented in usable increments have an advantage.

\section{Promote Objectivity}

While the urban transportation planning process cannot (and should not) remove politics from decisionmaking, the process should promote the separation of politics from forecasting and impact analysis. The role-indeed, the ethical responsibility of the transportation planner should be to provide objective analysis in a public forum that allows elected decisionmakers to make informed political tradeoffs. As those with experience in the process will attest, this is easier said than done. The specific recommendations of this and the next major section are designed to promote objectivity so that political tradeoffs are made based on our best available technical analysis.

Incorporate Independent Peer Reviews. All of us have experienced instances in which our close day-to-day participation in a project has blinded us to factors that are evident to outsiders. It is easy to get so involved in a project that we "cannot see the forest for the trees."

It is recommended that the preparation of regional transportation plans, major corridor analyses, and major activity center studies incorporate a new task, an outside professional peer review. Effective peer reviews can serve as a check on basic input assumptions, technical procedures, demand forecasts, cost estimates, and the whole range of socio-political bias. Part of the task of the peer review would be to document uncertainties and assumptions (explicit and implied). 
The benefits of a peer review process can best be ensured if the peer panel is sponsored by an organization with a measure of independence from the study being reviewed. In the case of projects involving large sums of federal dollars, it might be appropriate if the cognizant federal agency assembles and retains a peer panel from outside the geographic region. At the state level, it might be appropriate for the state department of transportation to retain an outside peer panel as a condition of expending large sums of state dollars.

Separate Planning from Implementation. One of the most obvious factors working against objective development of capital improvements is conflict of interest of agencies and firms with a vested interest in capital intensive solutions. In Florida, we have seen the creation of regional commuter rail authorities charged with studying and implementing commuter rail systems. What happens if objective study shows that a rail system is unwarranted? There is merit to the classical separation of regional planning and project implementation, as it requires implementing agencies to have the endorsement of the metropolitan planning organization as a condition of project implementation. This requirement promotes comprehensive analysis of alternatives.

Regrettably, we cannot always rely on professional consultants to evaluate objectively the feasibility of major capital projects when they have millions of dollars in design fees riding on a favorable decision. It is recommended that, when consulting firms are retained for technical assistance in evaluating alternatives, conflict-of-interest considerations should dictate that firms involved in the planning analysis be prohibited from a major role in the design contracts. While many consulting firms have a high degree of ethics and can be relied upon to exercise objective judgment without regard to future contracts, the motivations for bias are too strong to overlook.

\section{Place the Consequences of Risk with Decisionmakers}

When the bulk of the cost burden of major capital investments for a given locality is borne by others, there is little incentive to make careful decisions on resource commitments. This is particularly true of discretionary projects, and in the current vernacular, "demonstration projects," which translate to political ear- 
marking. An intelligent resource allocation system should be one in which the risks of aecepting optimistic forecasts of demand, cost, etc., are borne by the group making implementation decisions. A number of specific measures can support this recommendation.

Broad Formula Grants. One measure that ISTEA promoted was to reduce the number of categorical limitations on application of federal funds. There is considerable merit to the allocation of federal and state support by means of broad formula grants that allow substantial local discretion as to which specific projects are undertaken, without regard to categorical limitations and differences in matching ratios. To the extent that local officials are required to allocate fixed funding amounts, the consequences of poor decisions would rest more squarely on local shoulders. If local decisions were poor, local areas would suffer, with no hope of state or federal bailout.

Another alternative, suggested by Polzin (1995), would limit the federal commitment to major transit capital investments to a fixed amount per passenger carried, thereby placing the risks of optimistic demand and cost estimates squarely on the shoulders of local decisionmakers.

Increase Local Funding Responsibilities. Another measure is to reduce federal support for local transportation investments, placing more of the funding burden on state and local agencies, which, in turn, are more dependent on local sources of tax support. Though the relative merits of shifting more responsibility for funding to the state and local level will be evaluated in the political arena, there can be little doubt that placing funding responsibility at the same level at which implementation decisions are made will hold local officials much more accountable for rational decisionmaking.

\section{Closing}

Uncertainty is pervasive in all of our planning activities. Yet, we plan as if we could take a snapshot 20 years into the future and devise an optimal solution to that snapshot. We ignore and even disguise the limitations of our methods and fail to develop contingencies for the uncertainties that may arise. 
It is believed that the implementation of the approaches outlined in this paper will allow us to recognize uncertainty, yet not be paralyzed by it; to move proactively toward the attainment of valued societal objectives, yet be prepared for the changes we cannot predict.

\section{References}

Ascher, W. 1978. Forecasting: An appraisal for policymakers and planners. Baltimore, MD: The Johns Hopkins University Press.

Barr, Dunlop \& Associates, Inc. 1970. Tampa urban area transportation study: A summary report. Prepared for the Florida Department of Transportation.

Behn, R. D., and J. W. Vaupel. 1982. Quick analysis for busy decision-makers. New York: Basic Books, Inc.

Center for Urban Transportation Research. 1995. State transportation policy initiative: A new strategic urban transportation planning process. Tampa: University of South Florida.

Chu, X., and S. E. Polzin. 1996. Considering build-later as an alternative in major investment analyses. Transportation Research Board 75th Annual Meeting, Washington, D.C., preprint.

Dawes, R. M. 1988. Rational choice in an uncertain world. New York: Harcourt Brace Jovanovich.

Fischoff, B. 1977. Perceived informativeness of facts. Journal of Experimental Psychology: Human Perceptions and Performance 3(2): 349-358.

Florida Department of Transportation. 1994. Trends and conditions, 2020 Florida transportation plan.

Hogarth, R. M. 1987. Judgment and choice: The psychology of decision, Second Edition. New York: John Wiley \& Sons.

Lowe, S. and M. G. Richards. 1983. Systematic sensitivity testing in project appraisala method of identifying the uncertainty of transportation forecasts. Proceedings, 10th Transportation Planning Colloquium. Delft, The Netherlands: 3-12.

Mackinder, I.H., and S. E. Evans. 1981. The predictive sccuracy of British transport studies in urban areas. Transport and Road Research Laboratory Supplementary Report 699. Crowthorne, Berkshire, England. 
Manheim, M. L. 1979. Fundamentals of transportation systems analysis. Cambridge, MA: The MIT Press.

Martinelli, D. R. 1994. A systematic review of busways. Harley O. Staggers National Transportation Center, West Virginia University.

Mierzejewski, E. A. 1996. An assessment of uncertainty and bias: Recommended modifications to the urban transportation planning process. Unpublished doctoral dissertation, University of South Florida.

Neumann, L. A., and W. Pecknold. 1973. Application of the time-staged strategic approach to systems planning. Highway Research Record 435: 20.

Pell, C. M., and A. H. Meyberg. 1983. The estimation and use of uncertain forecasts in urban transportation planning. Proceedings, 10th Transportation Planning Colloquium. Delft, The Netherlands: 15-27.

Peters, T. J., and R. H. Waterman, Jr. 1984). In search of excellence: Lessons from America's best-run companies. New York: Warner Books.

Pickrell, D. H. 1990. Urban rail transit projects: Forecast versus actual ridership and costs. U.S. Department of Transportation.

Polzin, S. E. 1995. Private communications. Center for Urban Transportation Research. Richmond, J. 1995. Transport of delight: The mythical conception of rail transit in Los Angeles. Working Paper ITS-WP-95-10. Institute of Transportation Studies, the University of Sydney.

Tversky, A., and D. Kahneman. 1974. Judgment under uncertainty: Heuristics and biases. Science 185: 1124-1131.

U.S. Department of Transportation and Environmental Protection Agency. 1993. Clean air through transportation: Challenges in meeting national air quality standards.

Wachs, M. 1986. Technique vs. advocacy in forecasting: A study of rail rapid transit. Urban Resources 4(1): 22-30.

\section{About the Author}

Edward A. Mierzejewski, Ph.D., P.E., is Deputy Director for Engineering at the Center for Urban Transportation Research at the University of South Florida in Tampa. 